\title{
DE RECUERDOS Y MEMORIAS EN LOS ÚLTIMOS EPISODIOS NACIONALES DE GALDÓS
}

\begin{abstract}
La mirada hacia sí mismo se nutre de memoria. El yo que vislumbramos es el resultado de una continuada reminiscencia, en la que aparecen los destellos de nuestra historia personal.
\end{abstract}

EMLIO LLEDÓ, Elogio de la infelicidad

Al escribir, ¿interpretamos hechos ya sucedidos o nos anticipamos a los hechos?

MENCHU GuTIÉRREZ, El ojo de Newton

...la memoria tiene lóbregos desvanes donde suelen parecer las cosas más olvidadas y perdidas $(P, \mathrm{XXVII})^{\perp}$.

Así se expresa el narrador cuando Santiaguito Ibero, protagonista de Prim y $L a$ de los tristes destinos, intenta recordar el nombre de una persona cuyas facciones ha reconocido, y no hay que esperar mucho a que ese nombre llegue de forma efectiva a los labios del personaje ("la memoria le dio con fulgor de relámpago el nombre del sujeto", se dice en el párrafo siguiente). Igual, seguramente, le aconteció a Galdós más de una vez en la composición de los últimos ocho episodios nacionales, que relatan los años finales del reinado de Isabel II, el posterior sexenio revolucionario y los albores de la Restauración. Y no es sólo que muchos de los eventos históricos que tienen lugar en ellos sean acontecimientos ya vividos por el joven Galdós, a quien, por tanto, le basta con recuperarlos de su memoria, sino que numerosos personajes secundarios y sucesos menores deben de proceder, como es lógico, de recuerdos del propio escritor: es lo que sucede, sin duda, con las abundantes referencias a periodistas y redacciones de prensa de una época en que él comenzaba a hacer sus primeros pinitos en una profesión en la que pronto destacó, llegando a ser director de El Debate; vivencias inmediatas son también los debates parlamentarios que aparecen en estas novelas y que tuvo que cubrir como periodista en la realidad (ahora los rescata para sus episodios simplemente "rebañando en su memoria", como dice que hace Ibero padre cuando cuenta a don Ángel Cordero "detalles interesantes de la votación" en que había sido elegido rey Amadeo de Saboya [ET, XXV]); recuerdos personales, en fin, asoman aquí y allá en estas obras, las cuales, según se afirma en una de ellas, se escriben "mezclando sabrosamente lo personal con lo histórico" ( $C$, III). Incluso el título de uno de estos episodios, La de los tristes destinos, que en su origen procede de Shakespeare (Ricardo III, acto IV, escena 4), es un recuerdo personal de Galdós, pues tal calificativo en referencia a la reina Isabel lo había utilizado,

1 Damos las referencias de las citas de los Episodios Nacionales a continuación de las mismas indicando episodio y capítulo y empleando las siguientes abreviaturas: P, Prim; $T$, La de los tristes destinos; ER, España sin rey; ET, España trágica; A, Amadeo I; PR, La Primera República; CS, De Cartago a Sagunto; C, Cánovas. 
en un discurso de $1865^{2}$, el político carlista Aparisi y Guijarro, quien, por cierto, aparece mencionado dos veces en España trágica (IX y XI).

Galdós se hace presente en estas ocho obras de forma más notoria según nos aproximamos al término de la quinta serie de episodios. Desde luego, sus gustos musicales se dejan traslucir cuando el narrador declara haber sido

parroquiano ferviente de la Sociedad de Conciertos [...]. Por ella han venido a ser el más puro recreo de nuestras almas las monumentales, las soberanas sinfonías de Beethoven y lo mejor del repertorio de Haydn, Mozart, Mendelssohn, Weber, Händel, Schubert, y demás genios de la gloriosa pléyade germánica $(C, \mathrm{XVI})$,

o cuando homenajea a Julián Gayarre asegurando que "voz de tenor tan fina y bien timbrada diz que no se ha oído jamás" $(C S, \mathrm{XXI})^{3}$.

La conocida afición pictórica de Galdós ${ }^{4}$ también queda de relieve en el último de los episodios en una visita de Tito y Casiana al Museo del Prado:

mi compañera se asimiló el valor estético de la pintura, supo apreciar a los maestros, y distinguía perfectamente a Velázquez del Tiziano y a Murillo de Rubens [...] continuamos admirando a Van Dick, Correggio, Velázquez, Rafael y el delicioso y minúsculo cuadro del Mantegna Las exequias de la Virgen (C, XVI).

En los cuatro episodios postreros la presencia del autor es, pues, ostensible; pero no hay duda de que ya en los anteriores su persona se manifiesta por doquier. Por ejemplo, gracias a que entre 1865 y enero de 1867 Galdós anotó de su puño y letra y uno por uno los libros que iba adquiriendo, podemos saber hoy que las lecturas del protagonista de España trágica, asiduo parroquiano del librero Durán, son las mismas del escritor en esa época: "casi todas las obras que aparecen como adquiridas por Vicente Halconero después de la Septembrina figuran entre las compradas por Galdós en estos meses finales de $1865 \mathrm{y}$, en menor número, salvo respecto de algún autor, en las de 1866"5.

Tampoco hay duda de que es a través de los ojos del propio novelista como presenciamos relevantes acontecimientos ya en los episodios finales de la cuarta serie. Un solo caso pero muy notable. Don Benito confesó en diversas ocasiones que un suceso de los que había vivido lo había conmocionado especialmente, el fusilamiento de los sargentos del cuartel de San Gil:

2 "Cette phrase avait dâ faire fortune à l'époque et rester gravée dans le souvenir de l'auteur, comme caractérisant le plus exactement le destin d'Isabelle II" (Robin, 1977: 215).

3 Tanto a la Sociedad de Conciertos como a muchos de los compositores citados laudatoriamente en Cánovas -e incluso al propio Gayarre- se refiere Galdós más por extenso en su artículo "La música" (cf. Pérez.Galdós, 2004: 693-699).

4 De la afición de Galdós a la música y a la pintura da fe Clarín en su esbozo biográfico del novelista canario (cf. apud Rogers, 1979: 39).

5 Pérez Vidal, 1987: 181. El registro bibliográfico llevado por Galdós se conserva en la Casa-Museo Pérez Galdós (cf. transcripción del mismo en ibíd., 213-226). 
Como espectáculo, tristísimo, el más trágico y siniestro que he visto en mi vida, mencionaré el paso de los sargentos de Artillería llevados al patíbulo en coches, de dos en dos, por la calle de Alcalá arriba, para fusilarlos en las tapias de la antigua plaza de toros ${ }^{6}$.

Pues bien, la sublevación y posterior derrota de los sargentos de ese cuartel es el motivo histórico elegido para cerrar Prim; con el traslado de los sargentos camino al paredón de fusilamiento se abrirá con fuerza particularmente dramática el siguiente episodio, La de los tristes destinos.

Y no sólo los sucesos históricos notables, sino también los hechos menudos, los detalles nimios de la vida cotidiana, las pequeñas cosas de que está llena la vida de una época se dan cita en los textos a partir de la experiencia personal del autor, que pasa a constituirse en material narrativo de las obras: "los hechos que ahora relataré fueron apreciados fácilmente por mi propio conocimiento, o por fidedignas referencias de los amigos" $(C, \mathrm{XIX})$.

Así pues, la memoria o el recuerdo se constituyen en materia literaria, pero no como materia en el sentido de tema o asunto (pues no son en absoluto la figura de Galdós o sus recuerdos el asunto de estos episodios nacionales), sino en el de materia nutricia de los textos, de humus que alimenta la ficción narrativa. Las lejanas vivencias almacenadas en la memoria sirven tanto de mantillo en el que crecen fértilmente los asuntos novelescos como de aceite lubricante del engranaje narrativo, de fuente de datos y experiencias en que beben los textos. Además, probablemente Galdós disfrutó trabajando de esa manera, como ya lo había hecho en enero de 1894 recordando a Núñez de Arce, quien había colaborado como él en el periódico El Debate en la época de gobierno del general Prim: "Lo explicaré relatando hechos pasados que, por lo insignificantes y lejanos, no constan en ningún archivo; pero yo los recuerdo bien, y me complazco mucho en ser historiador de ellos" (Pérez Galdós, 2004: 589). Y ocasión de complacerse a sus anchas tuvo, a no dudarlo, en los cientos de páginas de estas ocho novelas, que transcurren íntegramente en ese período histórico de su juventud madrileña. Para ello gozaba de un don que le permitió realizar esa tarea de bucear en sus recuerdos no sólo con complacencia sino también con seguridad: su muy buena memoria. Todavía algunos años después de acabar Cánovas, en un hermoso texto de 1915 en el que rememora el Madrid donde ha vivido tanto tiempo y del que recuerda con especial cariño sus años jóvenes, un Galdós ya muy quebrantado en su salud, al hablar de sí mismo en tercera persona, sigue mostrando, sin embargo, una confianza inquebrantable en su magnífica memoria: "en él se da el caso singular de que la Voluntad y la Inteligencia, ambas rendidas al cansancio, se inhiben totalmente, traspasando sus funciones a la Memoria, tanto más lozana cuanto más vieja, y siempre atisbadora y charlatana".

Esa mirada privilegiada de un observador tan atento de su tiempo es la que tenemos los lectores la fortuna de compartir en estos episodios, en los que se dan la mano el tiempo histórico y el tiempo del recuerdo, la realidad de la época y la novela de la vida, la

\footnotetext{
6 Pérez Galdós, 2004: 26. En otro lugar se refiere también Galdós en términos muy parecidos a la conducción de los sargentos de San Gil: "Estos sucesos -acabó don Benito- dejaron en mi alma vivísimo recuerdo y han influido considerablemente en mi temperamento literario" (Olmet, 1912: 30).

7 Pérez Galdós, 2004: 889. En este mismo texto, Guía espiritual de España. Madrid, insistirá un poco más abajo en que "mi memoria es muy fecunda" (ibid., 890).
} 
Historia con mayúsculas y la ficción, más o menos real o más o menos inventada, ficción cuyas borrosas fronteras entre lo biográfico auténtico y lo puramente imaginario le hacen formar parte -con más propiedad, pues, que en los episodios nacionales anteriores- de esa Historia del convulso período 1865-1880 que Galdós pretende contar a sus conciudadanos de 1907-1912.

Estamos, por consiguiente, ante un empeño de recuperación del tiempo pasado, pero no se trata de la búsqueda del temps perdu al estilo de Proust (aunque sí haya en cierta forma un temps retrouvé), porque en Galdós el propósito es muy otro: su intención no es ahondar sistemáticamente en los pliegues recónditos de la conciencia a la manera del escritor francés (quien, por cierto, empezó a forjar y luego a redactar la primera parte de su magna obra cabalmente por los mismos años en que Galdós escribía sus últimos episodios), sino iluminar desde los recuerdos de dentro los hechos de fuera. Dicho de otra forma, no se trata tanto de la objetivación literaria de la subjetividad profunda, cuanto de la proyección de lo subjetivo en lo objetivo, contribuyendo con ello a ensanchar la esfera de la objetividad misma, que integra así no sólo los acontecimientos históricos conocidos de la España de la época en cuestión y una gran cantidad de pormenores aparentemente insignificantes de la vida real del momento -al modo de la vasta Comedia humana de Balzac, autor determinante, dicho sea de paso, tanto para la obra proustiana como para la galdosiana-, sino también la asimilación que de ellos había hecho un sobresaliente testigo de la época, quien, desde la perspectiva de la distancia y del acervo de experiencia atesorada, nos devuelve ahora en sus textos el reflejo que aquellos sucesos habían dejado impreso en su memoria.

Así pues, nos encontramos en estos episodios a la vez con el periodista y escritor de 1865-1880 y con el ya consagrado autor de 1907-1912, que vuelca ahora sobre el pasado vivido su punto de vista presente, como, puestos a ello, no podía ser de otra manera, ya que, al fin y al cabo, el casi anciano don Benito no era en último extremo, igual que todo individuo, sino el conjunto de experiencias que lo habían constituido como tal, es decir: una suma de tiempo vivido. Y también lo mismo que a cualquiera, unas experiencias lo habían marcado de modo más determinante que otras. En este sentido, la etapa histórica a la que en estos episodios da forma novelada Galdós fue, con seguridad, esencial en su formación personal y literaria y, probablemente, una de las decisivas en su vida; no en vano es justo en esa época del sexenio revolucionario y aledaños en la que sitúa muchas de sus más grandes creaciones: a la cabeza de todas ellas Fortunata y Jacinta, pero también La desheredada, El doctor Centeno, Tormento, La de Bringas... Ya casi al final de su vida literaria, los nuevos episodios nacionales que se propone redactar lo llevan, por tanto, otra vez a ese espacio de tiempo particularmente feraz en su vida y en su obra.

Además, la distancia de cuatro decenios proporciona al gran novelista perspectiva más que suficiente no sólo para apreciar la importancia en lo personal de este período de su existencia, sino también para valorar el éxito o fracaso del proceso histórico que había tenido lugar en esos convulsos años. Por ello, aunque no son formalmente unas memorias de su autor estos ocho últimos episodios nacionales, sí que, por la cantidad de datos menores procedentes de la experiencia personal del novelista, podría decir Galdós -como en sus Memorias de ultratumba hace Chateaubriand, escritor alejado del español en tantas cosas, pero no en esto- que en ellos 
os hago ver el revés de los ácontecimientos que la Historia no muestra; la Historia no expone más que el derecho. Las Memorias tienen la ventaja de preservar uno y otro lado del tejido: desde este punto de vista, pintan mejor la Humanidad completa al exponer, como las tragedias de Shakespeare, las escenas altas y bajas (Chateaubriand, 2005: 1237).

En suma, Galdós relata en estos últimos episodios ya del siglo XX unos hechos trascendentes - la caída de una dinastía, la revolución triunfante, la entronización de un nuevo rey, la proclamación de la República, las sublevaciones cantonales, la última guerra carlista, los primeros años de la Restauración canovista- que vivió en su juventud y a los que asistió con la avidez informativa y capacidad retentiva propias de un joven. Pero ahora los recuerda, selecciona y presenta desde una edad más sabia, de mayor comprensión por la experiencia de los años y la acumulación de los conocimientos. Es, digamos, la historia de un perspicaz observador -el mejor de los de su tiempo, según mostró sobradamente en sus Novelas españolas contemporáneas-, contada por él mismo siendo ya casi un anciano, cuando los años le permiten una capacidad de discernimiento de los hechos y una perspectiva de los mismos vedadas al joven recién llegado a Madrid en los años sesenta del siglo XIX. O, por citar de nuevo las Memorias de Chateaubriand, puede decirse que en estos episodios de Galdós resulta cierto que "para juzgar imparcialmente la verdad que ha de quedar, es preciso, situarse en el punto de vista desde el cual la posteridad contemplará el hecho consumado" (ibíd., 1937).

Cuarenta años después de los sucesos narrados, Galdós mismo encarna ya en cierto modo esa posteridad y contempla como hecho consumado la derrota de la revolución otrora llamada Gloriosa y la deriva reaccionaria de la ulterior Restauración monárquica. Otra cosa es si eso lo hace imparcialmente, como pide el romántico francés, imparcialidad seguramente imposible incluso en la distancia, como tampoco son imparciales en absoluto -sino que de signo bien contrario- las Memorias del propio Chateaubriand, lo que ni en su caso ni en el de Galdós desmerece un ápice la calidad y hondura de sus obras. En concreto, no existe en estos episodios de Galdós la sensación -como, por ejemplo, sí la hay en Chateaubriand- de contemplar un mundo que se acaba definitivamente y atisbar uno nuevo que ha de llegar ineluctablemente. De lo que deja constancia Galdós es de la lucha de poderosas fuerzas contrapuestas que impiden el avance de la organización social en determinada dirección (liberal, democrática, progresista...), pero sin ambiente de liquidación del Antiguo Régimen, quizá porque éste como tal se da ya por finiquitado intelectualmente, aunque se halle bien presente todavía en la práctica (de ahí que menudeen las referencias a los denominados obstáculos tradicionales y a todo tipo de elementos retardatarios). $\mathrm{Y}$, desde luego, no tiene el lector de estos episodios galdosianos la impresión de cierta desolación existencial que sí puede embargar al lector de las Memorias del escritor francés, porque en Galdós no hay sensación de pérdida, sino, si acaso, de hastío, por la perduración todavía de las viejas rémoras que han frenado, cuando no impedido, la evolución hacia la modernidad social de la España del XIX.

Como bien se sabe, la fórmula narrativa de los episodios galdosianos consistió desde el primero de ellos en mezclar personajes históricos y personajes novelescos y entretejer los sucesos que protagonizaban aquéllos con las peripecias por que pasaban éstos. Así sigue siendo en los últimos episodios, pero con importantes novedades. Además de la aparición de personajes puramente fantásticos, muchos de ellos creados a partir de figu- 
ras mitológicas conocidas, resulta novedoso que bastantes de los personajes secundarios que pueblan estas novelas sean seres reales, conocidos de forma directa o no por el autor. Por otro lado, muchos de los personajes de ficción incorporan en su caracterización rasgos de otros reales en los que se inspira Galdós para individualizarlos. Obviamente, es imposible saber qué hay de un hipotético modelo real en cada personaje inventado y, desde luego, numerosos detalles se nos escapan hoy, pero, con todo, pueden comprobarse rasgos de personajes reales incorporados en otros ficticios, como, a decir verdad, había venido haciendo Galdós desde sus Novelas españolas contemporáneas.

La crítica ha señalado ya algunos de esos detalles biográficos que proceden del propio autor o de personajes cercanos a él: así, se ha dicho (cf. Beyrie, 1980: I, 119) que Juanito Maltrana, el amigo que recibe a Santiaguito Ibero a su llegada a Madrid en Prim, está inspirado en el paisano de Galdós Fernando León y Castillo, también mayor que él como Maltrana con respecto a Iberito, aunque no le llevaba seis años, sino escasos seis meses; asimismo parece un recuerdo personal, más que una mera coincidencia, el que una de las amantes de Tito, Obdulia, lo llame cariñosamente Mico, nombre de evidente similitud con el mimoso Miquiño que emplea en su correspondencia Pardo Bazán para referirse a Galdós (cf. Madariaga, 2001: 92).

A veces la presencia del autor en el texto puede producirse de forma oblicua, como seguramente ocurre en el siguiente caso de España trágica, cuando Segismundo pretende entrar en relaciones amorosas con la pía Donata (de nombre, por otro lado, zumbón: 'la que se da', con extraña y un tanto fetichista predilección por clérigos y asimilados) y para conquistarla le ofrece sacrificar su mundano bigote: "si usted lo manda, me afeitaré el bigote, este signo infamante del hombre libre, siervo de una sociedad profana, por no decir atea" (XI). Dado el rotundo bigote que Galdós lució a lo largo de su vida, poca duda cabe de que una guasona sonrisa debió de aflorarle a los labios cuando el libertino Segis ofreciera ese sacrificio (iy quién sabe si no habrá ahí un recuerdo todavía más personal!).

En España sin rey también puede existir cierto poso autobiográfico -más amargo en este caso-en el personaje de Céfora, la nerviosa y desequilibrada amante de Juan de Urríes, mística a ratos, dominada por la lujuria en otros, e hija "de una hermosa muchacha judía, llamada Mesooda, de familia pobre del gheto" (XVIII). Conociendo la relación sentimental de Galdós con Concha Morell, llamada Ruth cuando abrazó el judaísmo, y también emotivamente inestable como Céfora, es difícil que el autor no tuviera en mente a la persona real de Concha-Ruth Morell cuando construía su personaje de ficción 8 .

Aunque siempre resulta arriesgado suponer modelos reales en los personajes de ficción, no cabe sorprenderse de que el autor de los Episodios nacionales opere de ese modo. De hecho, se trata de un procedimiento muy característico del arte realista y naturalista, y de ello es perfectamente consciente el mismo Galdós cuando, refiriéndose a otro novelista, alaba sus obras justo por ser capaz de encarnar en los personajes rasgos de individuos reales:

...todas las demás calidades eminentes que avaloran las obras del insigne maestro no tendrían tanto realce si no campeara sobre ellas la individualidad de los caracteres, arrancados

8 Parece más evidente la relación entre Céfora y Concha Morell que la que se ha creído ver (cf. Madariaga, 2001: 106-107) entre la antigua amante galdosiana y el personaje medio fantástico, medio mitológico de Graziella, amante de Tito durante un tiempo y ayudante de Mariclío en los cuatro últimos episodios. 
del natural; no con la minuciosa atención fragmentaria del pintor que analiza en el modelo, sino sorprendidos de un solo golpe, como quien siente los caracteres en la vida real, los sorprende en los círculos de la amistad y de la familia, los encarna en las personas más queridas, en sí mismo tal vez, y asimilándose la figura, la expresa en el libro, y éste, como espejo milagroso, reproduce la imagen de quien lo escribe (Pérez Galdós, 2004: 609).

El entusiasmo con que Galdós subraya el uso de esta técnica en la obra del novelista amigo nos ilumina sobre lo que él mismo debía de considerar procedimiento clave en su propia labor novelesca. Para Galdós, la novela no es sólo, pues, a la manera stendhaliana, un espejo que se pasea por un ancho camino y refleja la realidad estática o incluso la realidad dinámica que por allí transita, sino que se trata ahora -más en la línea de la Alicia de A través del espejo de Carroll- de un espejo milagroso capaz de sorprender y arrancar del natural aspectos que pasan inadvertidos a un espejo de reflejo simple. Y lo que aún es mucho más significativo: en manos del novelista genial ese espejo es capaz de girar $\mathrm{y}$, vuelto hacia el propio autor, devolvernos la imagen de quien escribe. Cuánto más cierto es esto en los últimos episodios nacionales, en los que el escritor vuelve la mirada hacia el tiempo en que se formó como escritor y hacia el hombre que fue.

El novelista al que se refería Galdós en las líneas anteriores era su amigo Pereda, de quien hablaba tan encarecidamente en ocasión muy dada a ello, pues se trataba del discurso de respuesta al de ingreso en la Academia del escritor cántabro, tan separado de Galdós en lo ideológico como próximo en lo personal. Muy conocida es la filiación carlista de Pereda y la profunda antipatía del autor de los episodios por el carlismo y los carlistas, de lo que hay sobrada muestra en los episodios de la quinta serie. . Sin embargo, no siempre es Galdós sañudo con los carlistas. Salva en algunos de ellos su buena intención, su idealismo trasnochado, su españolismo caballeroso... Es el caso de Wifredo Romarate, el protagonista de España sin rey, cuyo tipo quijotesco revela lo anacrónico de su posición política, pero cuya integridad personal la ve con simpatía su creador, exactamente igual que en la realidad le ocurría con Pereda, quien ofrece sugerentes analogías parciales con el personaje de ficción. Si Galdós aplaude en el novelista de Polanco el recurso de individualizar a los personajes incorporando en ellos rasgos de figuras reales familiares al autor, no sería muy osado imaginar que cuando él, como novelista, pretenda presentar medio positivamente a un personaje afín al carlismo, tenga en cuenta ciertas cualidades que advierte en Pereda: caballerosidad, firmeza de principios, etc. Y, en efecto, dichos atributos son los que adornan al caballero vitoriano don Wifredo Romarate.

También en el citado discurso de respuesta de Galdós, hay una peculiaridad que Pereda, como tantos conservadores decimonónicos, comparte con otro personaje carlista de estos episodios -aunque no cántabro de Polanco, sino vasco de Durango-, el padre de Tito: ambos odian las grandes ciudades. Así dice Galdós de Pereda:

nuestro ilustre amigo, entre otras rarezas de su carácter, siente un grande aborrecimiento de las ciudades populosas, que interponen entre su espíritu y la Naturaleza grueso mural

9 Véanse dos ejemplos entre otros muchos posibles: "aquellos hombres fanáticos, que subordinaban toda ley de humanidad a las absurdas pretensiones de un rey de fantasía", "era un carlistón rabioso, fanático, muy cerrado de mollera" (CS, XV y XXII, respectivamente). 
de calles antipáticas, de caseríos repletos, de gentes frívolas, embusteras y maleantes. Ama con pasión exclusiva los valles melancólicos de su tierra... (Pérez Galdós, 2004: 614).

Y así se expresa el padre de Tito:

Hijo mío, creo que sólo con sacarte del laberinto de ese Madrid arrastrado y disoluto, te curarás de tus murrias y del desvarío de tu cabeza. Te inficionaron los miasmas del vicio y de la corruptela, ¿no entiendes lo que te digo?...; pues corruptela quiere decir el burlarse de las leyes de Dios, el no amarle ni temerle, el andar en el tole tole de libertades, que yo llamo licencias, y el querer meternos a los españoles en un fregado de ideas pestíferas y, como quien dice, republicanas. Te lo diré más claro... En los aires limpios del pueblo soltarás toda esa podredumbre, y serás otro hombre... ( $A$, XIV).

Sin duda, cuando Galdós hace hablar a su personaje le induce a desvelar con claridad las razones de su odio al mundo urbano, mientras que cuando se refiere a Pereda lo presenta de forma mucho más sutil, como no podía ser de otro modo dadas las circunstancias y el personaje.

Pero no debemos confundirnos con respecto a estos últimos episodios nacionales suponiendo que detrás de los personajes de ficción se ocultan personajes reales, pues no se trata en absoluto romans à clef. Lo importante es que -se haya inspirado o no Galdós en determinados individuos reales para dotar de mayor ilusión de verdad a los caracteres ficticios de las figuras de sus novelas- se produce en estas ocho obras una clara interferencia entre lo histórico, lo vivido y lo fingido. Ello hace que la frontera entre esos tres planos resulte con frecuencia borrosa e, incluso, que se tenga la impresión de que Galdós lleva deliberadamente al lector a sentir cierto efecto de sustitución de uno de esos tres niveles narrativos por cualquiera de los otros dos, de modo que no se está siempre seguro de si determinado pasaje de tal o cual novela ha de entenderse como crónica histórica, relato autobiográfico o pura ficción.

Es más, el autor no sólo incluye personajes históricos importantes o secundarios en sus episodios y toma rasgos de algunos otros para construir más verosímilmente ciertos personajes ficticios, sino que rescata también personajes de aquellas Novelas españolas contemporáneas ambientadas en la misma época en que suceden estos episodios históricos contemporáneos. De esta forma, es como si en alguna medida los textos literarios en que el autor había objetivado un proceso histórico más de veinte años antes se convirtieran necesariamente en tejido configurador de los textos que vuelven mucho tiempo después sobre el mismo período histórico. El autor parece verse impelido, pues, a considerar la creación del nuevo texto como reescritura de textos previos, con los que, en cierto modo, acaba constituyendo un texto único, una obra total, por lo que podría afirmarse que, sin llegar al extremo del borgiano Pierre Menard y su reescritura literal del Quijote, también estos episodios nacionales crean, a su manera, sus propios precursores.

Verdad es que, en sentido estricto, esta técnica de traer a los episodios personajes de las novelas contemporáneas sólo era posible en los últimos episodios, que se desarrollan cronológicamente en época idéntica o cercana a la de algunas de sus grandes novelas (Fortunata y las demás que hemos mencionado más arriba). Por ello, nos volvemos a encontrar en estos episodios al ínclito don José Ido del Sagrario, al no menos notable 
Francisco de Torquemada, a Francisco Bringas, Plácido Estupiñá, etc., personajes todos bien conocidos para los lectores de las novelas galdosianas. Como es sabido, Galdós había observado ya tal técnica en las obras de su admirado Balzac y le saca todo su partido al procedimiento al incorporar a estas novelas históricas personajes de sus otras novelas, aquellas que sólo en cierto sentido podemos llamar no-históricas, porque, desde luego, en lo esencial también son históricas y por eso comparten con estos episodios no sólo el espacio y tiempo referenciales, sino también, según venimos diciendo, personajes, situaciones, ambientes y, en definitiva, el mismo entramado vital y social. Ello contribuye a dar unidad al universo narrativo galdosiano enlazando al final de su carrera literaria en estos postreros episodios las dos líneas de su narrativa: novelas contemporáneas y episodios nacionales, éstos ahora, pasado el tiempo, también contemporáneos. Lo cual no es más que la brillante culminación de un rasgo (la concepción de la obra en su conjunto como un todo) que ya había advertido sagazmente Menéndez Pelayo en 1897 en el inteligente análisis -más allá de las diferencias ideológicas que en él manifiesta- que lleva a cabo de la trayectoria novelística de Galdós al responder al discurso de ingreso de éste en la Academia:

La falta de selección en los elementos de la realidad; la prolija acumulación de los detalles, en esa selva de novelas que, aisladamente consideradas, suelen no tener ni principio ni fin, sino que brotan las unas de las otras con enmarañada y prolífica vegetación, indican que el autor procura remedar el oleaje de la vida individual y social, y aspira, temerariamente quizá, pero con temeridad heroica, sólo permitida a tan grandes ingenios como el suyo y el de Balzac, a la integridad de la representación humana, y por ella a la creación de un microcosmos poético, de un mundo de representaciones enteramente suyo, en que cada novela no puede ser más que un fragmento de la novela total, por lo mismo que en el mundo nada empieza ni acaba en un momento dado, sino que toda acción es contigua y simultánea con otras (apud Rogers, 1979: 70).

Pero reaparecen no sólo personajes de sus otras novelas, sino también muchos provenientes de episodios anteriores, que, en diversas ocasiones, prolongan sagas familiares, caso del mismo Santiaguito Ibero, hijo de don Santiago Ibero, el protagonista de varios episodios de la Tercera Serie -quien asimismo aparece en algunos de estos últimos-, o de Vicente Halconero, hijo de Lucila Ansúrez, perteneciente a la fecunda y muy significativa familia de los Ansúrez, de capital importancia en los episodios de la Cuarta Serie. Consigue con ello Galdós dar la impresión de vida en sucesión que refleja los avatares del tiempo histórico que transcurre sin pausa, de forma muy parecida a lo que hace Zola con sus Rougon-Macquart en paralelo con el devenir del Segundo Imperio napoleónico (por cierto, un período cronológico, 1852-1870, casi parejo al de las dos series finales de episodios galdosianos). El mismo Galdós es perfectamente consciente de esa sensación de vida social que proporcionan los personajes secundarios de las novelas si éstos están trazados con mano maestra, y así lo pone de manifiesto en un texto algo anterior a los últimos episodios, el prólogo que acompaña a la tercera edición de La Regenta en 1901: "No debemos olvidar a Carraspique, ni a Barinaga, ni a la turbamulta de figuras secundarias que dan la total impresión de la vida colectiva, heterogénea, con picantes matices y espléndida variedad de acentos y fisonomías" (Pérez Galdós, 2004: 222). En referencia 
a su propio quehacer literario, y ya después de haber escrito Cánovas, Galdós explica en 1913, en el prefacio a la traducción francesa de Misericordia, ahora que puede tener una perspectiva casi completa de toda su obra, el propósito que le ha guiado al hacer reaparecer numerosos personajes en distintas novelas suyas:

Diferentes figuras vinieron a este tomo de los anteriores, El amigo Manso, Miau, los Torquemadas, etc., y del mismo modo, del continente de Misericordia pasaron otras a los tomos que escribí después: es el sistema que he seguido siempre de formar un mundo complejo, heterogéneo y variadísimo, para dar idea de la muchedumbre social en un período determinado de la Historia (ibíd., 186-187).

Así pues, es el interés por dar cuenta en sus novelas de la diversidad del espacio urbano moderno, de la importancia de la muchedumbre en el nuevo entramado social que constituye el dominio de la gran ciudad y de la maraña de relaciones sociales, económicas y políticas que se establecen en ese nuevo ámbito en constante transformación lo que mueve a Galdós a emplear el procedimiento técnico de traer de acá para allá personajes de sus obras de tal suerte que los distintos hilos de la urdimbre se entrecrucen para dar la sensación de densidad vital, social e histórica que corresponde a la complejidad del mundo contemporáneo.

En esta línea, los últimos episodios nacionales representan un postrer esfuerzo del novelista por dar respuesta literaria a esa creciente complejidad. No hay más que compararlos con los primeros episodios para observar la evolución que se ha producido y la distancia que hay desde una novela como Trafalgar, que en determinado sentido podemos llamar épica (evidentemente, épica de la derrota, como obligan los mitos fundacionales de la nación), a una obra como Cánovas, que sin gran dificultad podríamos considerar medio memorística o semiautobiográfica. Para llegar hasta aquí Galdós ha realizado previamente la magna empresa de retratar la sociedad española de su tiempo en sus Novelas españolas contemporáneas. Que se ha cumplido un ciclo completo es algo evidente, y no sólo en la esfera literaria, sino también en el ámbito ideológico-político. Concluye además en estos episodios toda una idea de España. Galdós ejemplifica admirablemente tal cosa con la reaparición en La Primera República de un venerable viejo de nombre simbólico, Juan Elcano, que estuvo en la de Trafalgar y que se encuentra ahora combatiendo al lado de los cantonalistas de Cartagena. Este personaje morirá en el episodio siguiente, conectando de forma asimismo simbólica la derrota de Trafalgar y la del Cantón y dejando también traslucir en ello Galdós el fracaso de sus propios ideales:

Entre la muchedumbre encontré al veterano de Trafalgar, Juan Elcano, que ansiaba reverdecer sus marchitos laureles. Gesticulando con sus manos tembliconas me dijo que si le daban un puesto en la muralla cumpliría como quien era. [...] Al atardecer de aquel mismo día supe que el veterano de Trafalgar, consecuente con su destino heroico, había muerto en la muralla defendiendo la idea cantonalista, última cristalización de su patriotismo $(C S, \mathrm{~V})$.

En realidad, la insólita orientación de la obra galdosiana en el siglo xx es paralela a la de la mejor novela contemporánea; salvando las distancias, es la evolución que se 
produce en la novela francesa entre la obra de un Balzac y la de un Proust. Galdós no es, desde luego, Proust, pero sus episodios finales ya se despegan claramente del realismo decimonónico y apuntan el nuevo camino hacia una novela más introspectiva. De hecho, en estos episodios el novelista literaturiza no sólo su juventud, sino también sus ideales derrotados (Prim, Amadeo...), sus ilusiones perdidas, su decepción. De ahí que incluso en algunos momentos pueda advertirse una cierta pulsión lírica en este último Galdós, puesto que, recordando a Antonio Machado, sólo "se canta lo que se pierde". Así, el narrador de Cánovas -prácticamente confundido con el autor, como diremos enseguida-, después de quedar desconcertado al recibir la noticia del golpe de estado de Martínez Campos en Sagunto y creer ver en los transeúntes con que tropieza "moderados o alfonsinos orondos, insolentes, pavoneándose en celebración de su triunfo" (II), al final del día, refugiado en una taberna, experimentará la siguiente sensación:

Sobre mi alma iba cayendo un velo de tristeza desgarrada, por cuyos intersticios veía las caras de los hombrachos que rodeaban la mesa, y oía jirones de una charla política tocante a la venida de los higos chumbos, o como dijo Paja Larga, del elemento alfonsino... (II).

Pero dentro de este desencanto perdura casi siempre en el viejo escritor su optimismo de raíz liberal o positivista, que le permite albergar la esperanza de un futuro en el que aquellos antiguos ideales puedan consumarse, ahora bajo la forma de la República, lo que es patente tanto en las obras que escribe por estos años como en su personal actividad política en ese momento como miembro de la Conjunción Republicano-Socialista. Tal optimismo aleja a Galdós del pesimismo existencial ya en boga en su época y, más aún, del nihilismo que en distinto grado puede observarse en notables autores del fin de siglo. Galdós, acogiéndose a veces a la sabiduría popular, otras al racionalismo del mismísimo $\mathrm{Pi} \mathrm{i}$ Margall ${ }^{10}$, considera que el tiempo es "reparador solícito de las desdichas humanas" (PR, XIII):

El tiempo, amigo Ido, que es la cifra y compendio de la disciplina, pues nada puede alterar el régimen pausado de sus horas, sus días y sus años, se encargará de poner término a.esas calamidades... (PR, XII).

Referencias a múltiples individuos de la época, desde los más eminentes a muchos otros sin particular relieve en la Historia, incorporación de rasgos de figuras reales conocidas por el autor a sus entes de ficción, reaparición de personajes de sus anteriores novelas y episodios a estos con que va a concluir su examen histórico del siglo XIX español, todo ello es ciertamente de capital importancia para la comprensión de estos textos, pero lo que en verdad resulta de indudable novedad en su obra es lo que el propio autor pone de sí mismo en las muchas páginas de estas ocho novelas, donde recuerda los ambientes en que se movió en el Madrid de 1864-1880. Bien es cierto que sus recuerdos nunca traspasan la esfera de las relaciones sociales, políticas o profesionales. Galdós se cuida mucho (a diferencia de un Rousseau, un Chateaubriand o un Proust) de ser el protagonista directo de sus obras, y por eso en ellas la propia intimidad está ausente y no

10 "pensaba como yo (lo digo sin vanidad) que la razón y el tiempo, las dos fuerzas eternamente disciplinadas e incontrastables..." ( $P R, \mathrm{XII})$. 
invade en absoluto los territorios de la historia novelada, lo que es coherente tanto con el género literario en que se inscriben los Episodios nacionales -proyectados por definición hacia lo objetivo y no hacia lo subjetivo- como con la proverbial discreción de Galdós en cuanto atañía a su persona. $\mathrm{Y}$, sin embargo -y ello hace particularmente interesantes estas obras-, el autor está muy a menudo presente en ellas, y de forma casi constante en las cuatro finales, a través sobre todo del personaje narrador, Tito Liviano, que se dice amigo suyo. La conversión de Galdós en personaje es transparente pese a omitir con tacto su nombre:

nos habíamos conocido y tratado en una casa de huéspedes donde juntos hacíamos vida estudiantil. Él era guanche [...] él despuntaba por la literatura; no sé si en aquellas calendas había dado al público algún libro; años adelante lanzó más de uno, de materia y finalidad patrióticas, contando guerras, disturbios y casos públicos y particulares que vienen a ser como toques o bosquejos fugaces del carácter nacional. A mí también me da el naipe por las letras; pero carezco de la perseverancia que a mi amigo le sobra. Ambos, en la época que llamaré amadeísta, matábamos el tiempo y engañábamos las ilusiones haciendo periodismo, excelente aprendizaje para mayores empresas $(A, \mathbf{I})$.

En otros capítulos Galdós se autodenominará el canario o el isleño, y será él quien de forma expresa recurra al expediente de encargar a Tito la redacción del texto cuando se encuentren no por casualidad el año en que se escribe Amadeo I:

En la Puerta del Sol nos encontramos a los treinta y siete años justos del día en que tomó el portante don Amadeo de Saboya. [...] Hablamos de trabajos y publicaciones; díjele yo que había leído las suyas, y él, replicándome que algo le quedaba por hacer, saltó con esta idea que a las pocas palabras se convirtió en proposición:

-Una promesa indiscreta oblígame a escribir algo de aquel reinadillo de don Amadeo, que sólo duró dos años y treinta y nueve días. Tú y yo vimos y entendimos lo que pasó y lo que dejó de pasar entonces. Tu memoria es excelente; sabes contar con amenidad los sucesos públicos. Hazme ese libro, y con ello quedará saldada la deuda de caridad que tienes conmigo. Puedes observar el método que quieras, ateniéndote a la cronología en lo culminante y zafándote de ella en los casos privados, aunque éstos a veces llegan al fondo de la verdad más que llegan los públicos $(A, \mathrm{~V})$.

El interesante personaje de Tito será en muchas ocasiones un álter ego de su autor, con quien a veces llega a confundirse por completo. Esta identificación plena entre creador y personaje se advierte, por ejemplo, en el capítulo XXIV de Cánovas, cuando Tito se atribuye sin rebozo las páginas escritas por Galdós años atrás sobre Estupiñá: "Al pasar por la calle de Sevilla entramos en la tienda de mi amigo Matías Luengo, sobrino del famoso comerciante, parlanchín y entrometido don Plácido Estupiñá, de quien tanto hablé en diferentes ocasiones".

De hecho, incluso podría concebirse la palabra Tito como aféresis de Benito. Es más, cuando en Amadeo I se encuentran Estévanez y Tito, ambos se saludan respectivamente como don Nicolás y don Tito: "Bastante más joven que él era yo, y por la edad, como por el respeto, solía llamarle don Nicolás. Él me devolvía la fineza llamándome 
burlonamente don Tito" (XI). Si tenemos en cuenta que, en efecto, Nicolás Estévanez era mayor que Galdós y que asimismo era canario como él, no sería muy aventurado suponer que en esta escena se filtre un recuerdo personal del novelista, a quien Estévanez llamaría también burlonamente don Benito e incluso, quizá, don Tito. Por otro lado, el nombre de Tito tampoco es ajeno al entorno personal de Galdós, quien pone tal nombre a un perro vagabundo con el que se queda ("Es bonito, de raza pura fox terrier y le he puesto el nombre de Tito"11), precisamente cuando se encuentra redactando en su casa santanderina de San Quintín uno de nuestros episodios, según comenta en carta de 1 de septiembre de 1911:

Voy a mandar a Victoriano que retrate al perrito, el cual he bautizado con el nombre de Tito.

Es un niño perruno con todas las gracias y las porquerías propias de la edad infantil.

Avanzo mucho en la obra De Cartago a Sagunto, y creo no equivocarme mucho al decir que va saliendo muy bonita. ${ }^{12}$

Las coincidencias entre el joven Galdós y el protagonista-narrador de sus cuatro últimos episodios son abundantes. Nos limitamos a señalar algunas: ambos trabajan en El Debate, uno en la realidad y otro en la ficción, a las órdenes de José Luis Albareda ( $A$, IV); Tito, como Galdós, es amadeísta ("en los tiempos para mí venturosos de don Amadeo I", $C, \mathrm{XX}$ ); el personaje, igual que su creador, admira a Ruiz Zorrilla y, sin embargo, escribe contra él y su partido en El Debate, tal y como había hecho Galdós en La Nación; común afición a la lectura de periódicos ("Habituado a la lectura matinal de mis periódicos favoritos, el vacío de prensa me causaba tristeza", $C, \mathrm{III}$ ); conocimiento directo de muchos periodistas (véase, por ejemplo, las amables referencias a Carlos Frontaura, Campo Arana, Puente y Brañas, Pepe Fernández Bremón en $C$, IV); entrevista de Sagasta con Tito para animarle a integrarse en su partido y posterior ofrecimiento de un acta de diputado por el mismo -acta que aceptó Galdós en 1886- $(C$, XVII y XXIV, respectivamente), etc.

El paralelismo biográfico entre personaje y autor es particularmente intenso y patético con ocasión de la ceguera que padece Tito $(C, \mathrm{XII})$, trance en el que incluso interviene con su nombre y apellido Pablo Nougués, en guiño literario de Galdós hacia su secretario y amanuense. La proyección autobiográfica del escritor en el último de sus episodios es palmaria en el júbilo que experimenta su personaje cuando recobra la visión:

lo más importante para mí era el acentuado restablecimiento de mis ojos, y la reconquista de la facultad visual perdida en largos y dolorosos meses. Los que no han vivido en tinie-

11 Carta a T. Gandarias de 28-VIII-1911, apud Nuez, 1993: 233.

12 Ibid., 233-234. Repárese en la curiosa similitud entre los rasgos del protagonista de los cuatro últimos episodios y los que Galdós atribuye al perrito: pequeño, gracioso, infantil, de raza pura... Burlescamente, también Tito es personaje de raza: "Por mi padre tengo sangre de los Pipaones y Landázuris de Álava, absolutistas hasta la rabia, y sangre de los Torrijos y Porlieres, mártires de la Libertad. Mi madre me ha transmitido sangre de verdugos como González Moreno y Calomarde, sangre de Zurbanos, y aun la de fieros demagogos, ateos y masones. Mi abolengo es, pues, de una variedad harto jocosa. Yo, con paciencia y saliva, quiero decir tinta, he reconstruido mi árbol, y en él tengo señoras linajudas, títulos de Castilla, que casi se dan la mano con logreros y mercachifles de baja estofa; tengo un obispo católico, un cura protestante, una madre abadesa, dos gitanos, una moza del partido, un caballero del hábito de Santiago y varios que lo fueron de industria..." ( $A, \mathrm{II})$. 
blas por más o menos tiempo no conocen el purísimo, inefable gozo de ver y contemplar hombres y cosas, lo feo y lo bonito, la Naturaleza toda en la plenitud de sus maravillosos aspectos. Es como vivir de nuevo. Yo resucité, yo renací, y difícilmente puedo expresar mi alegría $(\mathrm{XV})$.

También parece clara la superposición de autor y personaje-narrador cuando el yo narrativo excede al propio personaje y, como el viejo yo del Lazarillo, ocupa abiertamente las páginas de la narración distanciándose de sus propios textos periodísticos de la época: "Yo debía decir [...]. Vi [...]. Oí [...] No sé si me explico bien. [...].Yo, dejando a un lado la reseña oficial escrita para mi periódico, daré a los beneméritos lectores de estas páginas la veraz impresión de un honrado testigo" $(A$, IIII). Ese ostentoso yo se desborda cuando el tema del que se ocupa toca en lo vivo al Galdós republicano de los años en que redacta estos episodios. Así ocurre, por ejemplo, en el penúltimo párrafo del capítulo XXI de Amadeo I, cuando, al tratar del iluso "optimismo de los revolucionarios sencillotes y pillines, que creen lo que sueñan", el narrador es mucho más que un honrado testigo y manifiesta vehementemente sus opiniones sobre el asunto.

Pero la aparición de Galdós como personaje en sus textos ya puede advertirse, aunque nunca directamente, en algún episodio anterior a los narrados por Tito. Así, en España trágica, Vicentito Halconero y su amigo Segismundo pasan algunos ratos en la tertulia del café Universal de la Puerta del Sol, donde "se reunían los canarios, servidos por Pepe el Malagueño. Era una tertulia de las más amenas de Madrid, compuesta de estudiantes de Derecho, de Medicina y de Caminos, y reforzada por personas mayores curtidas de marrullería y experiencia" (IV). Que uno de esos estudiantes canarios de Derecho era el propio Galdós es indudable, pues sabemos que asistía a esa tertulia, como sabemos de la existencia real de Pepe el Malagueño, a quien el joven Galdós -siempre buen dibujante-caricaturizó cumpliendo con su función de servir las mesas del café. El viejo escritor sigue recordando con afecto a ese camarero con quien se había cruzado tantos años antes:

Corrieron allí de boca en boca noticias [...], muchas de ellas transmitidas por el verbo inconsciente del Malagueño, que de mesa en mesa llevaba con el servicio sus fantásticos discursos. No ha existido mozo de café que en tan alto grado poseyera el don de las peroratas hinchadas y burlescas para divertir a los parroquianos (ET, IV).

Y no sólo recuerda Galdós la figura del personaje, sino sus particularidades lingüísticas, según observamos en los diálogos en que participa, e incluso los gestos que el camarero intercalaba en apoyo de sus palabras: "Y el Malagueño respondió besándose los dedos: - Por esta cruz, que nada oí de ese desacierto..." (ET, IV). Ya había salido en otro episodio anterior este personaje, que sin duda había dejado huella en la memoria de Galdós. Concretamente, aparece junto al dueño del café Universal (también dibujado por Galdós) con motivo de la Exposición Universal de París de 1867:

Entraron en el restaurant, donde Rubio y Clavería saborearon la ilusión de hallarse en el Café Universal de Madrid, pues allí estaba el dueño, don Juan Quevedo, un astur amable y narigudo; allí Pepe el Malagueño, brujuleando de mesa en mesa, siempre zaragatero y servicial $(T, \mathrm{XXI})$. 
Precisamente los recuerdos parisinos del joven Galdós, quien visitó en 1867 la Exposición Universal acompañando a un cuñado y a un sobrino, pasan en buena medida a estas novelas a través de la vista del asimismo joven Santiago Ibero, el cual, con mirada seguramente no muy distinta de la que dirigió su creador muchos años atrás al deslumbrante París del final del Segundo Imperio, contempla desde su esencial inocencia el nuevo mundo que desfila ante sus ojos. Mirada del personaje y mirada del escritor que, como tantas veces en estos episodios, se confunden en una sola para percibir con especial agudeza no sólo la realidad social y política del momento, sino también el bullicio de la vida humana que va de allá para acá por los bulevares parisinos convertida ya en la muchedumbre característica de la metrópoli moderna.

Pero conviene insistir en que en la memoria galdosiana (a diferencia de lo que ocurre en la obra de Chateaubriand y de tantos otros escritores) no existe exactamente nostalgia por el tiempo pretérito, no se cae en esa típica trampa psicológica que hace creer mejor cualquier tiempo pasado. Históricamente, Galdós sabe que eso no es tal; sólo es cierto que él era más joven, pero tiene buen cuidado de no convertirse en protagonista del texto transformando la narración en añoranza de la juventud perdida. Galdós presenta la revolución del 68, el reinado de Amadeo y la Primera República como oportunidades perdidas, pero sin nostalgia, pues no desconoce que aquello no pudo ser porque la correlación de fuerzas sociales no lo consentía y porque los propios errores de los revolucionarios, amadeístas y republicanos condenaron al fracaso sus respectivos intentos de renovación de la sociedad española. En rigor, no hay, pues, en estos episodios galdosianos experiencia de pérdida, como sí la hay indudablemente en Chateaubriand; no existe, desde luego, en los episodios añoranza alguna de un modo de vida que desaparece, porque la perspectiva de la memoria galdosiana es muy distinta. La memoria en Galdós no está al servicio de la tradición, sino, si vale la simplificación, al servicio del progreso, de una utopía progresista que ha de ir por un camino muy distinto al acomodaticio de la política y la sociedad españolas de la Restauración. En este sentido, estas últimas obras de Galdós tienen un importante punto de contacto con las del ilustre escritor francés citado: en ambos casos la memoria del pasado presenta un carácter de resistencia ante la marcha del mundo, pero mientras que los ideales de aquel escritor conservador se encuentran en el pasado, los de Galdós apuntan hacia el futuro. Cierto es, además, que uno y otro, en su rechazo del mundo contemporáneo, alcanzan también a revelar en sus escritos la despersonalización del individuo en la sociedad burguesa donde los objetos se alzan muy por encima de los sujetos. En el caso de estos últimos episodios nacionales, ello se percibe en la disolución del héroe novelesco, con las hondas implicaciones que ello tiene, crucial asunto en el que no podemos extendernos aquí.

Así pues, la memoria de Galdós, su desdoblamiento en Tito, su desengaño del 68, sus ilusiones frustradas no suponen en estos episodios un recrearse en un pasado que pudo haber sido y no fue, sino que, al modo clásico, considerando la Historia magistra vitae, el autor pretende extraer de la historia española reciente y de la propia experiencia personal del pasado las lecciones que deben servir para no repetir los mismos errores en el futuro. Así lo dice explícitamente Tito-Galdós en el último capítulo de La Primera República:

Al retirarme, vi en mi mente con absoluta claridad que mi papel en el mundo no era determinar los acontecimientos, sino observarlos y con vulgar manera describirlos para que de 
ellos pudieran sacar alguna enseñanza los venideros hombres. De tales enseñanzas podía resultar que acelerasen el paso las generaciones destinadas a llevarnos a la plenitud de los tiempos. Seguí, pues, en mi atalaya histórica, y presencié fríamente...

Pero los hechos de la España de los años sesenta y setenta de que se trata en estos episodios no están en realidad observados fríamente desde una olímpica atalaya por aquel joven Galdós que vivió ese convulso período histórico, sino por el avezado escritor que contempla el pasado desde un presente ${ }^{13}$ también conflictivo, en el que interviene tanto desde su activa militancia política (copresidente de la Conjunción RepublicanoSocialista, diputado republicano en Cortes, etc.), como desde su reconocido trabajo como escritor. Galdós, al ver el pasado desde el más inmediato presente, escribe en estos episodios no ya sólo novelas históricas y, en parte, memorísticas, sino también novelas políticas propias de un escritor comprometido, engagé en el pleno sentido sartriano del término, algo que, por otra parte, y salvando las muchas distancias ideológicas y de estilo, había hecho ya en su primera novela publicada, La Fontana de Oro, al relacionar también entonces los sucesos del presente (el período revolucionario abierto con la Gloriosa) con un pasado histórico relativamente próximo (el Trienio liberal). El narrador de De Cartago a Sagunto, al afirmar que "escribo estas líneas cuando el paso de los años y de provechosas experiencias me han dado toda la claridad necesaria para iluminar el 2 de mayo de 1874" (XVIII), es expresamente consciente de este punto de vista desplazado en el tiempo que le permite juzgar el pasado con el conocimiento de las consecuencias sobrevenidas, cuya determinante influencia llega hasta el presente del autor y sus lectores. Galdós, pues, encuentra en sus últimos episodios la posibilidad de hacer coincidir su presente personal y literario con su lejana juventud y sus ilusiones entonces derrotadas y hoy renovadas.

La ocasión de extraer del pasado las lecciones oportunas para el presente político no puede ser más idónea, puesto que en estos últimos episodios ha de novelar el período del sexenio revolucionario, incluida la efímera Primera República, justo en el momento en que él se ve inmerso de pleno en la construcción de una nueva alternativa republicana cuando el sistema canovista está ya en claro declive. A la luz de ese paralelismo político entre el pasado y el presente se comprenden más apropiadamente las reconvenciones que dirige Tito en diversas ocasiones a los republicanos decimonónicos, desangrados por luchas intestinas, en evidente referencia a la desunión de los republicanos del siglo Xx, minados por personalismos y disputas de toda clase. Baste un ejemplo de este procedimiento por el que, cuando se dirige el narrador a aquellos políticos del 73 , debe entender el lector que se refiere acremente a estos políticos de 1911:

En los escaños retumbó el estruendoso clamor de ¡Todos somos unos! ‘Todos somos unos para defender la República! Al oír esto no pude contenerme. Se me encendió la sangre, y con toda la fuerza de mis pulmones lancé al hemiciclo estas palabras:

13 Con gran agudeza había señalado ya Casalduero este cambio de perspectiva desde el pasado al presente en estos últimos episodios nacionales: "El Galdós joven iba a la historia en busca de experiencia; el Galdós viejo, con su experiencia encuentra el significado de la Historia. Antes, hacía depender el presente del pasado; de manera positivista se consideraba el presente como efecto del pasado, la causa; ahora, ve cómo todo el pasado se organiza e interpreta desde el presente" (1974: 170). 
- iA buenas horas mangas verdes! Majaderos fuisteis; sed ahora ciudadanos y dejaos matar en vuestros asientos.

En el espantoso vocerío perdiéronse mis apóstrofes $(C S, \mathbb{X X})$.

Así increpa Tito en la ficción literaria a los diputados congregados en el Congreso en el instante en que se produce el golpe de estado de Pavía contra el legítimo gobierno republicano. Y en el episodio siguiente, ya de 1912, cuando la división entre los republicanos se ha consumado en la práctica (no en vano nuestro novelista había advertido en 1910 que el Partido Republicano "está pudriéndose por la inmensa gusanera de caciques y caciquillos. Tienen más que los monárquicos"14), un desolado Tito-Galdós expresa su desengaño:

Si nada se puede esperar de las turbas monárquicas, tampoco debemos tener fe en la grey revolucionaria. ¿Crees tú, Titillo, en la revolución?

- Yo no -contesté resueltamente-. No creo ni en los revolucionarios de nuevo cuño ni en los antediluvianos, esos que ya chillaban en los años anteriores al 68. La España que aspira a un cambio radical y violento de la política se está quedando, a mi entender, tan anémica como la otra. Han de pasar años, lustros tal vez, quizá medio siglo largo, antes que este régimen, atacado de tuberculosis étnica, sea sustituido por otro que traiga nueva sangre y nuevos focos de lumbre mental $(C, \mathrm{XX})$.

Con sorprendente acierto en su vaticinio, el álter ego galdosiano, en conversación que de forma imprecisa cabría situar hacia 1880, prevé la dilatada duración ("medio siglo largo") de la restaurada monarquía de los Borbones. Como se sabe, no será hasta el 14 de abril de 1931 cuando en España vuelva a proclamarse la República, consumación de la profecía galdosiana que hace buena la distinción entre el historiador y el poeta que establece Aristóteles en el noveno capítulo de su Poética: "la diferencia está en que uno dice lo que ha sucedido, y el otro, lo que podría suceder" (1974: 158).

14 Así se expresa Galdós en entrevista concedida a El Bachiller Corchuelo (González Fiol, 1910; apud Dendle, 1984: 92). Y en un mitin republicano de enero de 1911, alarmado por "las luchas que pudieran derivarse del revuelo de las ambiciones y de los efectos del antagonismo sectario y de la fe demasiado ardorosa", advierte de la necesidad de disipar "los recelos", de que la República "es obra de ideal y no de satisfacción de menguados apetitos" (Fuentes, 1982: 96). 


\section{BIBLIOGRAFIA}

Aristóteles (1974): Poética. Valentín García Yebra (ed.). Madrid: Gredos.

Beyrie, J. (1980): Galdós et son mythe. Libéralisme et christianisme en Espagne au xrxè siècle (1843-1873). 3 v. Lille: Université de Lille-Librairie H. Champion.

Casalduero, J. (1974): Vida y obra de Galdós (1843-1920). 4. a ed. Madrid: Gredos.

Chateaubriand, F. DE (2004): Memorias de ultratumba. Barcelona: Acantilado.

Dendle, B. J. (1984): "Galdós en El Año Político". En: Anales Galdosianos, 19, 87-108.

Fuentes, V. (1982): Galdós, demócrata y republicano. Escritos y discursos (1907-1913). Santa Cruz de Tenerife: Cabildo Insular de Gran Canaria-Universidad de La Laguna.

González Fiol, E., El BaChILler CorChuelo (1910): “Benito Pérez Galdós, confesiones de su vida y de su obra". En: Por esos mundos, 185 (junio de 1910), 789-807; 186 (julio de 1910), 26-56.

Madariaga de la Campa, B. (2001): Páginas galdosianas. Santander: Tantín.

Nuez Caballero, S. de la (1993): El último gran amor de Galdós: cartas a Teodosia Gandarias desde Santander (1907-1915). Santander: Ayuntamiento-Librería Estudio.

Olmet, L. A. del, y A. García Carraffa (1912): Galdós. Madrid: Imprenta de "Alrededor del Mundo".

Pérez Galdós, B. (2004): Prosa crítica. José-Carlos Mainer (ed.), Juan Carlos Ara Torralba (notas). Madrid: Espasa-Calpe.

Pérez Vidal, J. (1987): Galdós. Años de aprendizaje en Madrid, 1862-1868. Santa Cruz de Tenerife: Vicepresidencia del Gobiemo de Canarias.

Robin, C. N. (1977): "La de los tristes destinos: un roman historique tardif de B. Pérez Galdós". En: Albert Dérozier et al:: Recherches sur le roman historique en Europe (xvIIIè-XIXè siècles). París: Les Belles Lettres, 211-253.

Rogers, D. M. (ed.) (1979): Benito Pérez Galdós. 2. ${ }^{a}$ ed. Madrid: Taurus.

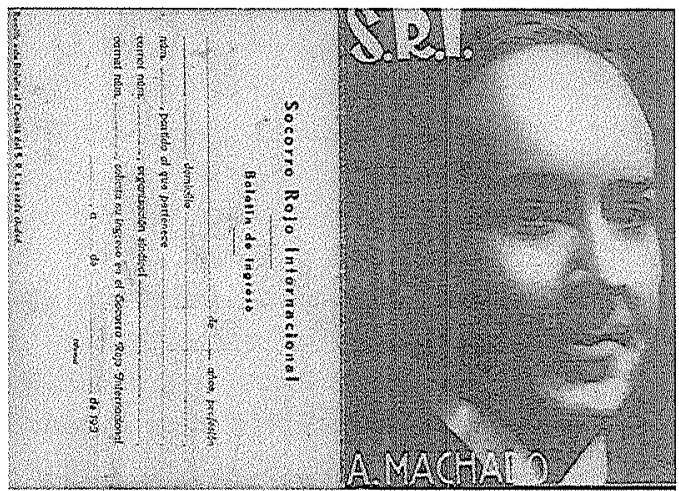

